\title{
Preparation and Epoxy Curing of Novel Dicyclopentadiene- Derived Mannich Amines
}

\author{
FENG-PO TSENG, ${ }^{1}$ FENG-CHIH CHANG, ${ }^{1}$ SHIAU-FENG LIN, ${ }^{2}$ JIANG-JEN LIN ${ }^{2}$ \\ ${ }^{1}$ Institute of Applied Chemistry, National Chiao-Tung University, Hsinchu, Taiwan, Republic of China \\ ${ }^{2}$ Department of Chemical Engineering, National Chung-Hsing University, Taichung, Taiwan, Republic of China
}

Received 17 March 1998; accepted 16 June 1998

\begin{abstract}
Phenol/dicyclopentadiene (DCPD) adducts were prepared from the $\mathrm{BF}_{3}$ catalyzed reaction of $p$-nonylphenol and dicyclopentadiene at molar ratios of $2: 1$ and $3: 2$. The phenol-terminating adducts were consequently reacted with diethylenetriamine and formaldehyde using Mannich reaction conditions. These products containing phenol, amine and tricyclodecane functionalities in the same molecule can be used as epoxy curing agents. The diethylenetriamine was add to the phenol via Mannich reaction at approximately $50 \%$ theoretical equivalent. The multiple $\mathrm{N}-\mathrm{H}$ groups in amines and the $\mathrm{O}-\mathrm{H}$ groups in phenols provide crosslinking sites for epoxy resins. The cured epoxy resins show improvement in tensile strength and elongation in comparison with those cured by the poly(oxypropylene) diamine (400 molecular weight) or diethylenetriamine. (C) 1999 John Wiley \& Sons, Inc. J Appl Polym Sci 71: 2129-2139, 1999
\end{abstract}

Key words: epoxy curing; Mannich amines; DCPD adducts

\section{INTRODUCTION}

Cyclopentadiene (CPD) is a byproduct of $\mathrm{C}_{5}$ streams in oil refineries. The CPD monomer exists in the form of dicyclopentadiene (DCPD), a dimeric adduct through Diels Alder reaction, at ambient temperature. DCPD is readily cracked into CPD at $170^{\circ} \mathrm{C}$. The high purity DCPD (95\%) can be widely applied as a comonomer in several polymer systems such as ethylene propylene diene monomer (EPDM), ${ }^{1,2}$ unsaturated polyester, ${ }^{3}$ olefin metathesis, ${ }^{4-9}$ and epoxy resins. ${ }^{10-12}$

In epoxy applications, DCPD-based novolac epoxy resins have the advantages of reduction in

Correspondence to: J. J. Lin.

Contract grant sponsors: the Chinese Petroleum Company and the National Science Council of Taiwan.

Journal of Applied Polymer Science, Vol. 71, 2129-2139 (1999)

(C) 1999 John Wiley \& Sons, Inc.

CCC 0021-8995/99/132129-11 epoxy cure shrinkage, moisture resistance, and retention of excellent electrical insulation properties. ${ }^{13-16}$ These features are very important for surface properties of composites and for delicate electronic applications.

The Mannich condensation of phenols, formaldehyde, and amines was first reported

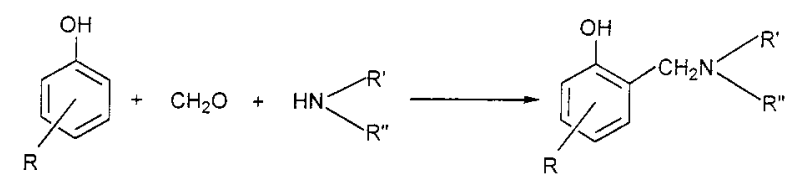

as early as $1942,{ }^{17}$ and has resulted in many industrial applications. ${ }^{18,19}$ The uses of various amines and alkylphenols produced materials useful for fine chemicals, ${ }^{20,21}$ polymers,${ }^{22-24}$ grease components, ${ }^{25}$ antifoulants, ${ }^{26}$ and fuel additives. ${ }^{27,28}$ In epoxy applications, the presence of phenol groups in Mannich condensates has the 

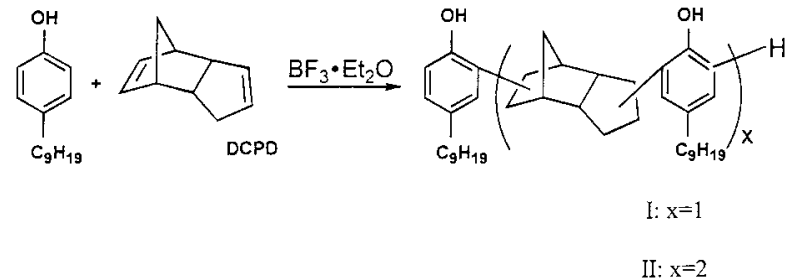

Scheme 1 Reaction of $p$-nonylphenol and dicyclopentadiene.

advantages of providing further reactive functions as well as an acceleration catalyst. ${ }^{29-31}$ It has been known that phenol-containing compounds, such as poly( $p$-vinylphenol) or 2,3,6-tris(dimethylaminomethyl)phenol, can function as an epoxy curing accelerator. ${ }^{32,33}$ Another advantage of using Mannich condensates is to convert the low molecular weight of poly(oxyalkylene)amines into prepolymers that are more suitable during epoxy curing process. The low molecular weight amines as epoxy curing agents usually generate brittle materials with too high a crosslinking density. The higher molecular weight analogs may overcome those disadvantages. The coupling of a low molecular weight poly(oxyethylene) diamine through carboxylic acid-derived amide is able to yield highly active epoxy curing agents. ${ }^{34}$

In this study, we prepare the Mannich condensates from DCPD-containing phenols as epoxy curing agents and investigate the relationships between mechanical properties of the cured polymers and molecular structure of amines curing agents. This synthesis involves two consecutive reactions, coupling the DCPD and $p$-nonylphenol by using $\mathrm{BF}_{3}$ catalyst, followed by a Mannich reaction to introduce amine moiety in the final structure.

\section{EXPERIMENTAL}

\section{Materials}

Liquid epoxy resin (BE-188) with an epoxide equivalent weight (EEW) of 188 was obtained from the Nan-Ya Chemical of Taiwan. Triphenylphosphine $\left(\mathrm{Ph}_{3} \mathrm{P}\right), p$-nonylphenol (NP), dicyclopentadiene (DCPD), boron trifluoride diethyl ether $\left(\mathrm{BF}_{3} \cdot \mathrm{Et}_{2} \mathrm{O}\right)$, formalin, and diethylenetriamine (DETA) were purchased from the Aldrich Co. Poly(oxypropylene) diamine at 400 molecular weight, i.e., Jeffamine ${ }^{R}$ D-400, was received from the Huntsman Co.

\section{$\mathrm{H}_{2} \mathrm{NCH}_{2} \mathrm{CH}_{2} \mathrm{NHCH}_{2} \mathrm{CH}_{2} \mathrm{NH}_{2}$}

\section{DETA}<smiles>CC(N)CC(C)C(N)N</smiles>

Poly(oxypropylene) diamine

\section{Syntheses of $p$-Nonylphenol and Dicyclopentadiene Adducts}

The preparation of dicyclopentadiene and phenol adducts was reported previously. ${ }^{35}$ To a 2 -liter

Table I Characteristic IR Absorptions for III and IV

\begin{tabular}{cl}
\hline Peak/Band $\left(\mathrm{cm}^{-1}\right)$ & \multicolumn{1}{c}{ Assignment } \\
\hline $3650-3200$ & $\mathrm{O}-\mathrm{H}$ stretch \\
$3400-3300$ & $\mathrm{~N}-\mathrm{H}$ stretch \\
3044 & Aromatic $\mathrm{C}-\mathrm{H}$ stretch \\
2960,2872 & $-\mathrm{CH}_{3}$ stretch \\
2930 & $-\mathrm{CH}_{2}$ stretch \\
$1610-1600$ & cyclopentenyl ring or aromatic $\mathrm{C}=\mathrm{C}$ stretch \\
$1510-1500$ & Aromatic ring $\mathrm{C}=\mathrm{C}$ stretch \\
1465 & $-\mathrm{CH}$ scissoring \\
1378,1365 & isopropyl and/or $t$-butyl $-\mathrm{CH} \mathrm{H}_{3}$ bending \\
1257,1244 & $t$-butyl backbond stretch (nonyl groups) \\
1180 & $\mathrm{C}-\mathrm{O}$ stretch $(\mathrm{phenol})$ \\
1120 & Aliphatic $\mathrm{C}-\mathrm{N}$ \\
$852-805$ & 1,4 - and/or $1,2,4$-substituted aromatic ring \\
$730-670$ & cis double-bond C-H bending \\
\hline
\end{tabular}



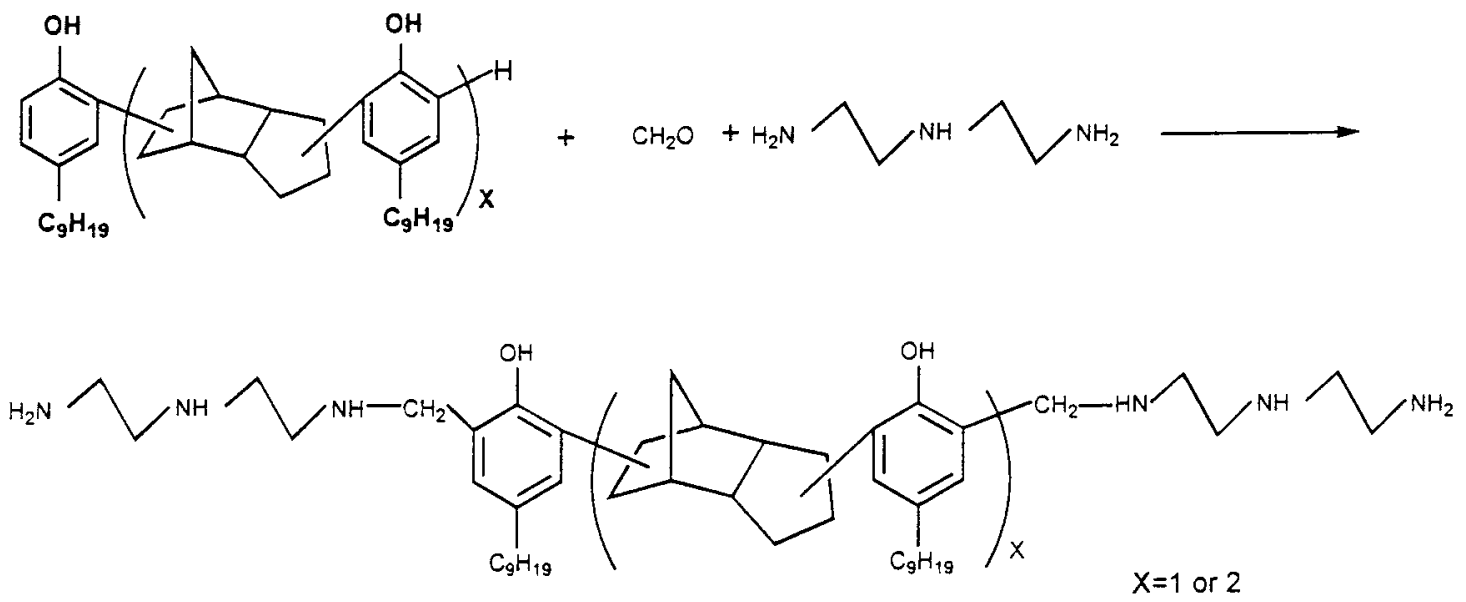

Scheme 2 Mannich reaction of $p$-nonylphenol/dicyclopentadiene.

four-necked flask equipped with a mechanical stirrer, nitrogen inlet, thermometer, Dean-Stark trap, and dropping funnel, $p$-nonylphenyl (440 g, $2.0 \mathrm{~mol})$ and $\mathrm{BF}_{3} \cdot \mathrm{Et}_{2} \mathrm{O}(2.2 \mathrm{~g})$ in toluene $(100 \mathrm{~g})$ were added. While stirring, the mixture was heated to $70^{\circ} \mathrm{C}$, held for $1 \mathrm{~h}$, and then cooled to $40^{\circ} \mathrm{C}$. At this temperature, DCPD $(132 \mathrm{~g}, 1.0 \mathrm{~mol})$ was added dropwise through an additional funnel over a 1-h period of time. During the addition, the exothermic temperature up to $53^{\circ} \mathrm{C}$ was observed. The temperature was then raised to $100-110^{\circ} \mathrm{C}$, held for $3 \mathrm{~h}$, and $130-150^{\circ} \mathrm{C}$ for additional $2 \mathrm{~h}$. At ambient temperature, the product mixture was extracted with 5 wt $\% \mathrm{NaOH}$ for at least three times to remove $\mathrm{BF}_{3}$ and impurities. The final product was subjected to a rotary evaporator under vacuum to give a black and viscous liquid (I). Using the similar procedures, the adduct of $p$ nonylphenol (440 g, $2.0 \mathrm{~mol}) / \mathrm{DCPD}$ (176 g, 1.3 mol) (mol ratio $3: 2$ ) was also prepared (II). The glass transition temperatures $\left(T_{g}\right)$ detected by DSC of I and II are -9.9 and $9.5^{\circ} \mathrm{C}$, respectively.

Adducts of $p$-nonylphenol and dicyclopentadiene at molar ratios of $2: 1$ and $3: 2$ were obtained as oligomers with representative structures I $(\mathrm{x}=1)$ and II $(\mathrm{x}=2)$, as shown in Scheme 1.

\section{Syntheses of $\boldsymbol{p}$-Nonylphenol/Dicyclopentadiene- Based Mannich Amines}

The Mannich amines can be prepared by an onepot synthesis during the reaction of NP and DCPD, without the $\mathrm{BF}_{3} \cdot \mathrm{Et}_{2} \mathrm{O}$ removal. As an example, DETA (206 g, 2 mol) was added into the DCPD/NP adducts $(472 \mathrm{~g}$, molar ratio $=1: 2$ or $616 \mathrm{~g}$, molar ratio $=2: 3$ ) prepared by the above procedures. While stirring, $37 \mathrm{wt} \%$ formalin (162 $\mathrm{g}, 2 \mathrm{~mol}$ ) was added over a 1 -h period of time. During the addition, the exothermic temperature up to $48^{\circ} \mathrm{C}$ was observed. The temperature was then raised to $80^{\circ} \mathrm{C}$, held for $3 \mathrm{~h}$, and $120-130^{\circ} \mathrm{C}$ for additional $2 \mathrm{~h}$. At ambient temperature, the product mixture was extracted with 5 wt $\% \mathrm{NaOH}$ for at least three times to separate the unreacted amines from the product. The final product was subjected to a rotary evaporator under vacuum to afford a viscous orange liquid. $p$-Nonylphenol/dicyclopentadiene/formalin/DETA at $2: 1: 2: 2$ and $3: 2: 2: 2$ molar ratios were obtained as oligomers with hypothetically representative structures described in Scheme 2.

\section{Curing Procedures}

Stoichiometric amounts of those prepared Mannich amine curing agents blended with poly(oxypropylene) diamine (Jeffamine ${ }^{\mathrm{R}} \mathrm{D}-400$ ) were employed to cure with the DGEBA (BE188). The general curing conditions are described: mixed at $70^{\circ} \mathrm{C}$, cooled to $50^{\circ} \mathrm{C}$, added $\mathrm{Ph}_{3} \mathrm{P}$ accelerator (two parts per hundred based on epoxy resin), and degassed at $50^{\circ} \mathrm{C}$ in a vacuum oven for $10 \mathrm{~min}$. The resultant mixture was then placed immediately into a preheated steel mold. The curing cycle was $50^{\circ} \mathrm{C}$ for $1 \mathrm{~h}$, $100^{\circ} \mathrm{C}$ for $1 \mathrm{~h}, 150^{\circ} \mathrm{C}$ for $2 \mathrm{~h}$, and $160^{\circ} \mathrm{C}$ for 1 additional hour. When the diethylenetriamine was involved, the mixing and degassing temperatures were at room temperature, and the curing cycle was $50^{\circ} \mathrm{C}$ for $1 \mathrm{~h}, 100^{\circ} \mathrm{C}$ for $1 \mathrm{~h}, 150^{\circ} \mathrm{C}$ for $2 \mathrm{~h}$, and $160^{\circ} \mathrm{C}$ for 1 additional hour. 


\section{Instrumental Analysis}

${ }^{1} \mathrm{H}-\mathrm{NMR}$ characterization was carried out by a Varrion VXR-300 (300 MHz) NMR spectrometer using $\mathrm{CDCl}_{3}$ as the solvent. FTIR spectra were obtained using a Nicolet 520 spectrometer. Gel permeation chromatography (GPC) was performed by a Water 410 differential refractometer at $40^{\circ} \mathrm{C}$ of the column temperature. Dynamic differential scanning calorimetry (DSC) was carried out on a Seiko DSC 5200 at a heating rate of $5^{\circ} \mathrm{C} / \mathrm{min}$ under a nitrogen atmosphere. Tensile properties were measured according to ASTM D638-86 at a testing rate of $5 \mathrm{~mm} / \mathrm{min}$, and flexural properties were measured according to ASTM D790 at a testing rate of $2.6 \mathrm{~mm} /$ min using an Instron machine. Notched Izod impact tests were carried out at ambient conditions according to ASTM D256. Amine contents were obtained based on ASTM D2073-92 titration method.

\section{RESULTS AND DISCUSSION}

\section{Syntheses and Characterization of p-Nonylphenol/ Dicyclopentadiene-Based Mannich Amines}

According to the result of amine titration, Mannich amine products III and IV have the total amine content of $3.80 \mathrm{mEq} / \mathrm{g}$ (theoretical 7.48 $\mathrm{mEq} / \mathrm{g}$ ) and $2.57 \mathrm{mEq} / \mathrm{g}$ (theoretical $5.20 \mathrm{mEq} /$ $\mathrm{g})$, respectively. This result indicates that about $50 \%$ of the DETA is attached to the products. The representative chemical structures of Mannich amine products III and IV are shown as below:

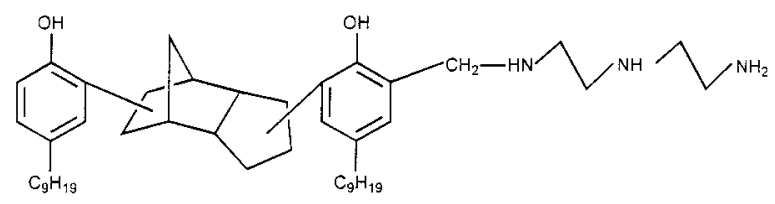

III

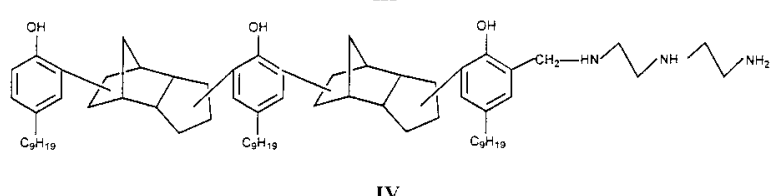

IV

The characteristic IR absorptions are listed in Table I. The FTIR spectra of analogous Mannich amine products III and IV are shown in Figure 1. The peak intensity at $2960 \mathrm{~cm}^{-1}\left(\mathrm{CH}_{3}\right.$ stretch) is stronger than that at $2930 \mathrm{~cm}^{-1}$
$\left(\mathrm{CH}_{2}\right.$ stretch), an indication of high branching of the nonyl group. The main alkene characteristic absorptions are $3100-3000 \mathrm{~cm}^{-1}(\mathrm{C}-\mathrm{H}$ stretch), $1680-1600 \mathrm{~cm}^{-1}(\mathrm{C}=\mathrm{C}$ stretch$)$, and $730-670 \mathrm{~cm}^{-1}$ (cis form of $\mathrm{C}-\mathrm{H}$, out of the plane bend). The absorptions at $3100-3000$ $\mathrm{cm}^{-1}$ and $1610-1600 \mathrm{~cm}^{-1}$ indicate the presence of the aromatic ring. The absorption peak intensity at $730-670 \mathrm{~cm}^{-1}$ (cis form of a double bond of $\mathrm{C}-\mathrm{H}$ bending) is rather weak, implying the absence of the DCPD starting material. Figure 1 also shows more absorption peaks at $3400-3300 \mathrm{~cm}^{-1}$ for the $\mathrm{N}-\mathrm{H}$ stretch and at $1120 \mathrm{~cm}^{-1}$ for the $\mathrm{C}-\mathrm{N}$ for the structure of diethylenetriamine (DETA). The water-soluble free DETA must be totally removed through extraction to make sure that the detected DETA is truly attached to these two analogs. The GPC analysis shown in Figure 2 also confirms that both Mannich amines III and IV are free of DETA. Additionally, Figure 2 shows that small amounts of the unreacted DCPD remained in both III and IV. This is consistent with the observation of FTIR spectra. Moreover, the GPC result shows the Mannich amine IV has higher average molecular weight than that of the III. The relative $M_{w}$ can also be verified indirectly by their glass transition temperatures $\left(T_{g} \mathrm{~s}\right)$, as shown in Table II and Figure 3. The Mannich amine IV has a higher $T_{g}\left(13.7^{\circ} \mathrm{C}\right)$ than product III $\left(-2.6^{\circ} \mathrm{C}\right)$.

${ }^{1} \mathrm{H}-\mathrm{NMR}$ spectra of products III and IV are given in Figure 4. The chemical shifts are: $\delta$ $=0.51-2.35 \mathrm{ppm}$ (saturated protons for nonyl group and DCPD), $\delta=2.60-2.81 \mathrm{ppm}\left(-\mathrm{CH}_{2}-\right.$ for DETA and DCPD), $\delta=3.73-3.97 \mathrm{ppm}$ $\left(\mathrm{Ph}-\mathrm{CH}_{2}-\mathrm{N}\right.$ linkage), $\delta=5.5$ and $5.7 \mathrm{ppm}$ ( $-\mathrm{CH}=\mathrm{CH}-$ for DCPD) and $\delta=6.65-7.20 \mathrm{ppm}$ (aromatic protons). The observed $\delta=3.73-3.97$ ppm is assigned to the $\mathrm{Ph}-\mathrm{CH}_{2}-\mathrm{N}$, which is characteristic of the Mannich amines. This result had been reported by Jamois et al. ${ }^{28,36,37}$

\section{Mechanical and Thermal Properties of Epoxy Resins \\ Product III and IV as Curing Agents}

A compound containing amine and hydroxyl functional groups in the same molecule has the ability to react with epoxy with different rates, and results in a sequential interpenetrating polymer network (IPN). Products III and IV are the Mannich adducts that possess DETA aliphatic amine, 


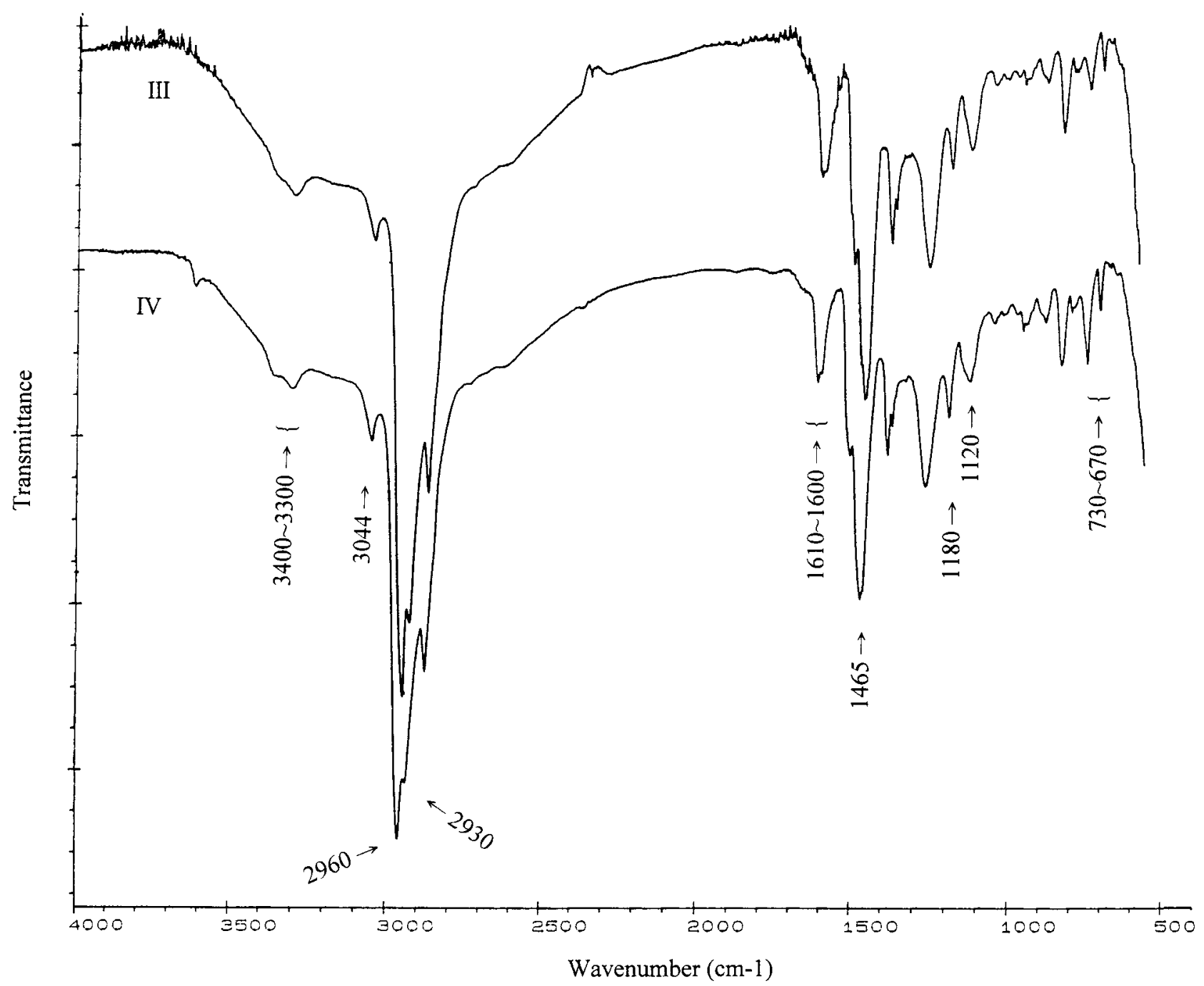

Figure 1 FTIR spectra of products III and IV.

$p$-nonylphenol, and tricyclodecane functionalities in the same molecule.

In the experiments, the code III' is to consider only the amine hydrogens $(-\mathrm{NH})$ of the structure III ( $-\mathrm{NH}$ functionalities $=4,-\mathrm{NH}$ equivalent $=172 \mathrm{~g} / \mathrm{Eq}$ ) in reacting with the epoxy resin. While the code III" takes into account both the amine hydrogens $(-\mathrm{NH})$ and phenolic hydroxyl groups
$(-\mathrm{OH})$ of the structure III $(-\mathrm{NH}+-\mathrm{OH}$ functionalities $=6,-\mathrm{NH}+-\mathrm{OH}$ equivalent $=114.7 \mathrm{~g} / \mathrm{Eq}$ ) in reacting with the epoxy resin. By the same definition, IV' (-NH functionalities $=4,-\mathrm{NH}$ equivalent $=260 \mathrm{~g} / \mathrm{Eq})$ and $\mathrm{IV}^{\prime \prime}(-\mathrm{NH}+-\mathrm{OH}$ functionalities $=7,-\mathrm{NH}+-\mathrm{OH}$ equivalent $=148.6 \mathrm{~g} / \mathrm{Eq}$ ) were employed for products IV in the IV'/BE-188 and IV"/BE-188 curing systems. 


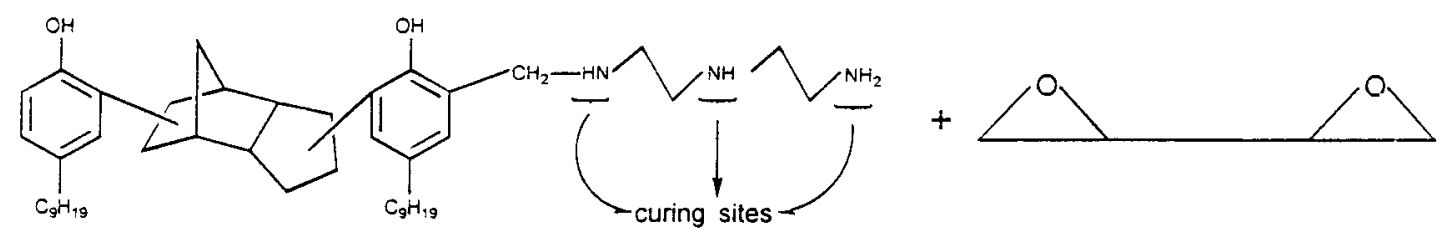

III $^{-}$

BE-188

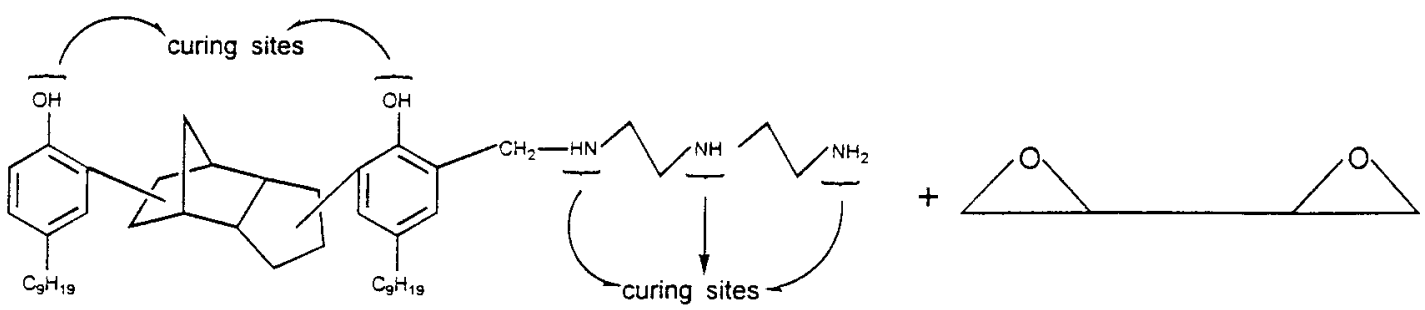

III"

BE-188

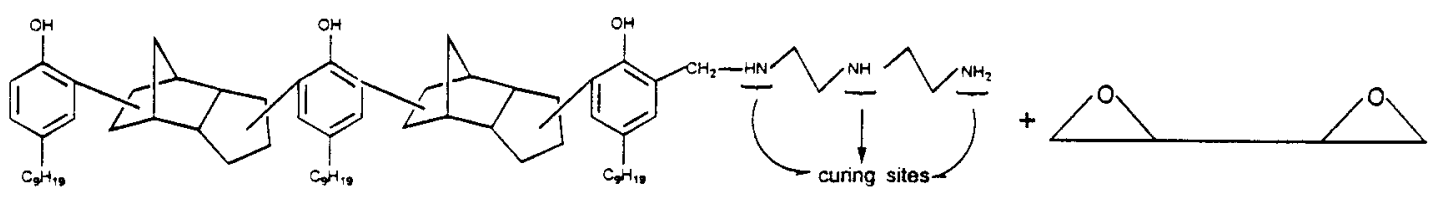

IV $^{-}$

BE-188

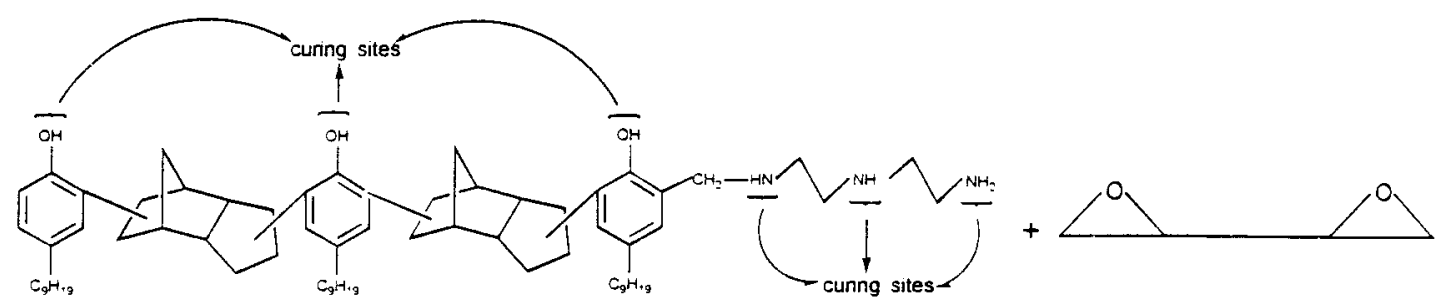

IV"

BE-188

$T_{g} \mathrm{~S}$ of DSC thermograms for the pure III', III", IV', and IV" cured products are shown in Figure 5. According to stoichiometric ratios, the III"/BE-188-cured polymer is expected to have higher crosslinking density and should possess higher $T_{g}$ than that of III'/BE-188. The experimental results show the opposite, which may be attributed to the molecular orientation of the Mannich amines. The multiple amines can be rapidly cured into a polymer network, which may trap residual unreactive $-\mathrm{OH}$ functionalities and limit further curing processes. Similar results were observed in the IV'/BE-188 and IV"/BE-188-cured polymers. 


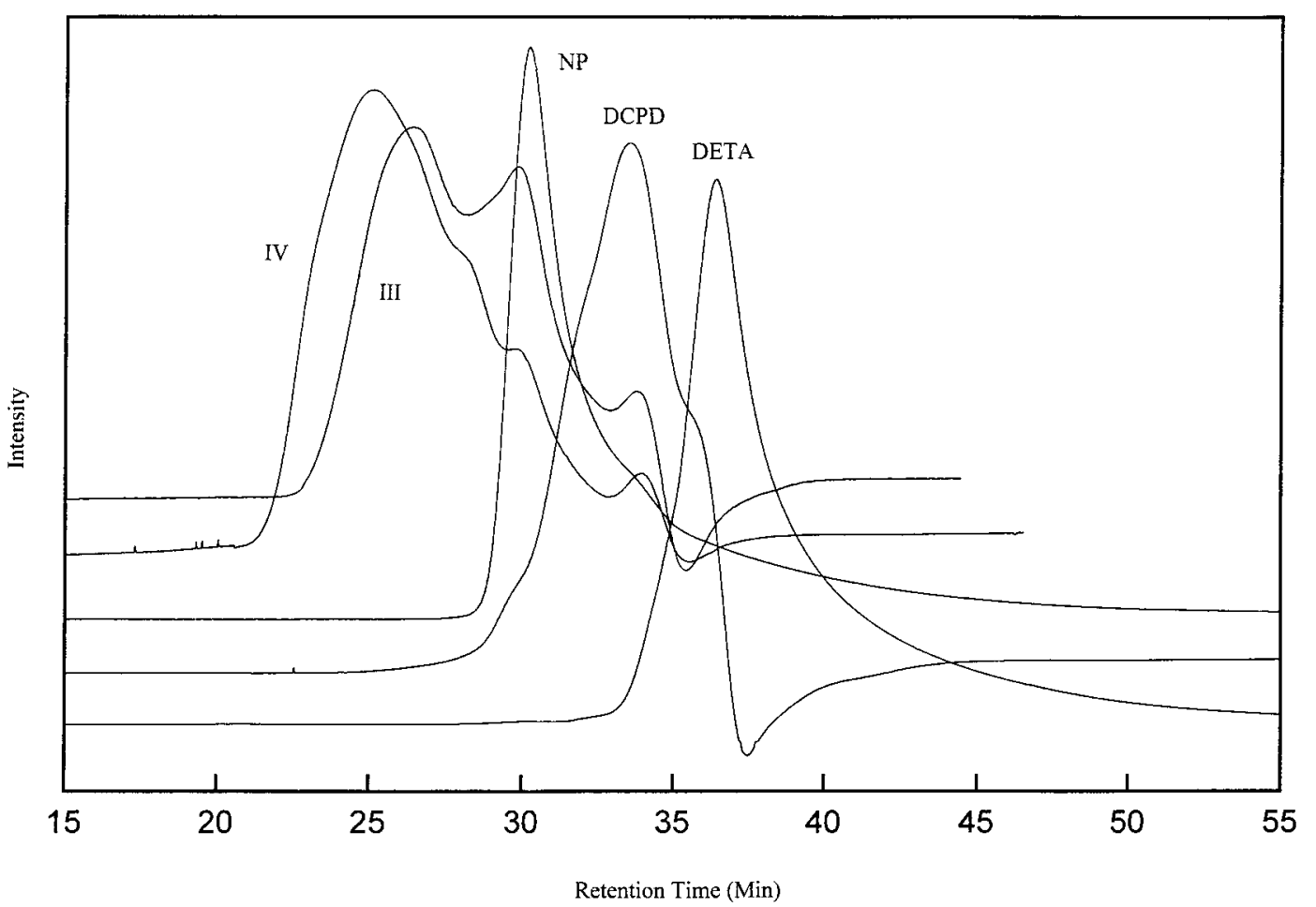

Figure 2 Relative GPC retention time of III, IV, NP, DCPD, and DETA.

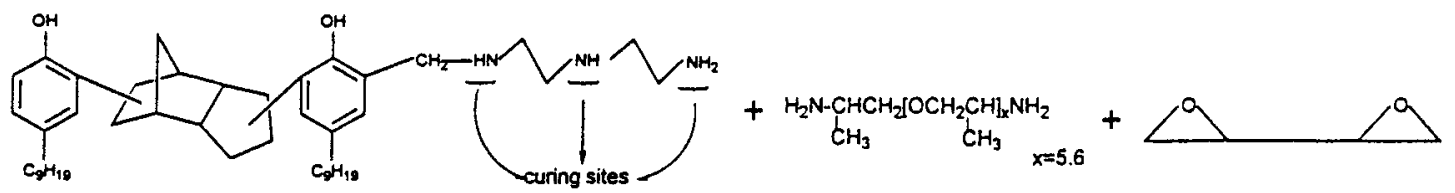

III

D-400

BE-188

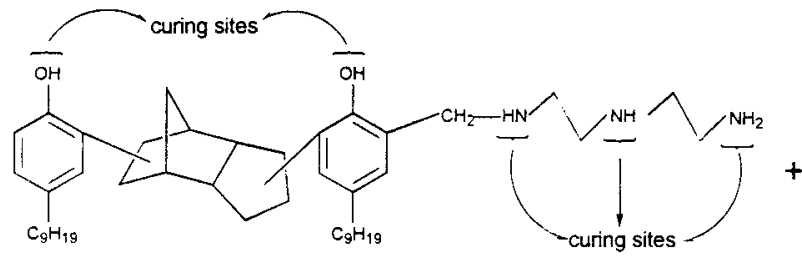

$+\underset{\mathrm{H}_{3}}{\mathrm{H} \mathrm{N}-\mathrm{CHCH}_{2} \mathrm{OCCH} \mathrm{CH}_{2} \mathrm{CH}_{2} \mathrm{NH}_{2}}+$

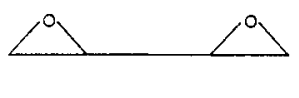

III"

$\mathrm{D}-400$

BE-188

\section{Product III Mixed with Polyetheramine as Curing Agents}

To improve the process in epoxy curing, the commercially available polyetheramine (Jeffamine D-400 amine) has been added. The addition of Jeffamine D-400 amine made the curing mixtures more pourable and improved the curing process.
Structures III' and III" represent the curing stoichiometry according to the amine and phenol functionalities, as described previously.

The mechanical properties for the cured materials are summarized in Table III. The III"/D-400/ BE-188-cured product is expected to have higher crosslinking density than that of III'/D-400/BE- 
Table II Glass Transition Temperature

\begin{tabular}{lcc}
\hline \multicolumn{1}{c}{ Composition } & Weight Fraction & $T_{g}\left({ }^{\circ} \mathrm{C}\right)$ \\
\hline Product III & & -2.6 \\
Product IV & & 13.7 \\
D-400/BE-188 & $35 / 65$ & 40.9 \\
DETA/BE-188 & $10 / 90$ & 140 \\
DETA/D-400/BE-188 & $5 / 18 / 77$ & 83 \\
III'/D-400/BE-188 & $29 / 13 / 58$ & 67.9 \\
III"/D-400/BE-188 & $25 / 12 / 63$ & 60.6 \\
IV'/D-400/BE-188 & $38.7 / 11.6 / 49.7$ & 68.9 \\
IV"/D-400/BE-188 & $32 / 10 / 58$ & 58.8 \\
\hline
\end{tabular}

188. As observed, the tensile strength improved slightly from 63.9 to $65.8 \mathrm{MPa}$, and the elongation decreased from 12.50 to $11.45 \%$. However, the $T_{g} \mathrm{~s}$ did not show the trend of higher crosslinking density (Table II, $60.6^{\circ} \mathrm{C}$ vs. $67.9^{\circ} \mathrm{C}$ ).

Curing of an epoxy resin with an amine may result in four possible reactions: primary amine-epoxy (PA-E), secondary amine-epoxy (SA-E), epoxy-epoxy (E-E) polymerization, and hydroxyl-epoxy (OH-E). Besides, phenolic hydroxyl groups in the system provide additional curing sites and also function as an accelerator. Relative extents of these reactions are mainly determined by the ratio of amine to epoxy groups ${ }^{38}$ and also the curing condition. ${ }^{39}$ It was reported that on the depletion of the PA-E reaction, SA-E and OH-E reactions become dominant and proceed at approximately the same rate. ${ }^{40}$ In the III"/D-400/BE-188-cured system, it is assumed that the PA-E and SA-E reactions

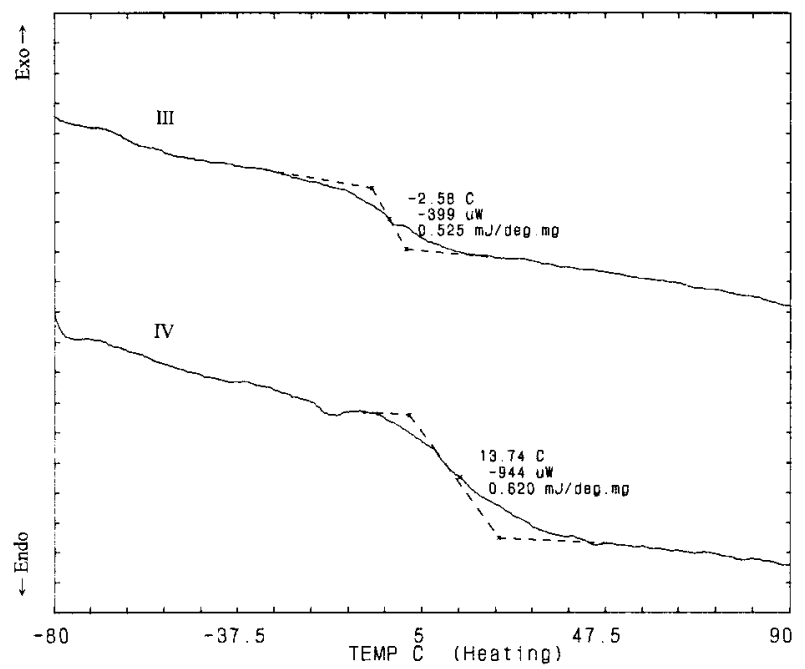

Figure 3 DSC thermograms of products III and IV. are faster than the $\mathrm{OH}-\mathrm{E}$ reaction (including phenolic hydroxyl-epoxy reaction). During the process of amine curing, the polymer molecular weight and entanglement increased and the pendant NP/DCPD phenol curing reactivity decreased accordingly. The unreacted low molecular weight epoxide could be trapped, and $T_{g} \mathrm{~s}$ were affected.

Mechanical properties of these two cured systems are compared with that of pure D-400 or

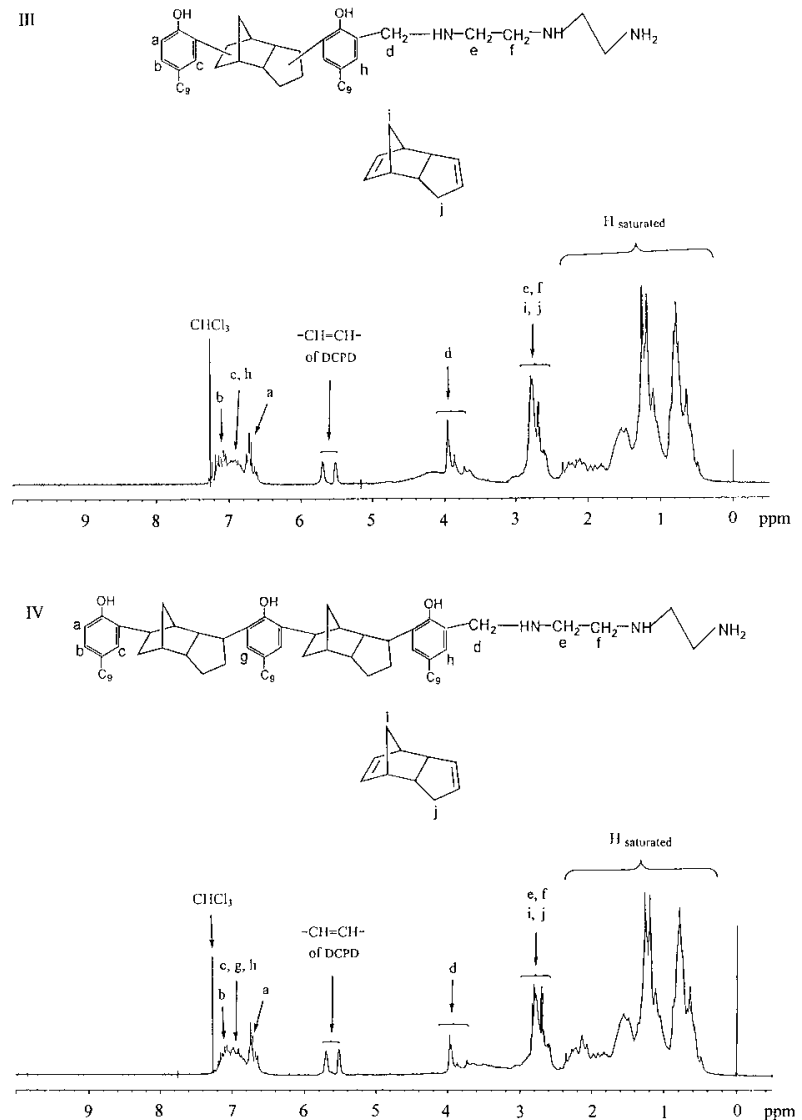

Figure $4{ }^{1} \mathrm{H}$-NMR spectra of products III and IV. 
DETA. The improvement of tensile strength and elongation properties are shown. Compared with the DETA/D-400 mixture, the mechanical properties of the DETA/D-400/BE-188 are similar to that of the III'/D-400/BE-188, except for

\section{Product IV Mixed with Polyetheramine as Curing Agents}

In the IV"/D-400/BE-188 system the tensile strength, elongation, and $T_{g} \mathrm{~s}$ are poor in comparison to the IV'/D-400/BE-188 system. Simi-
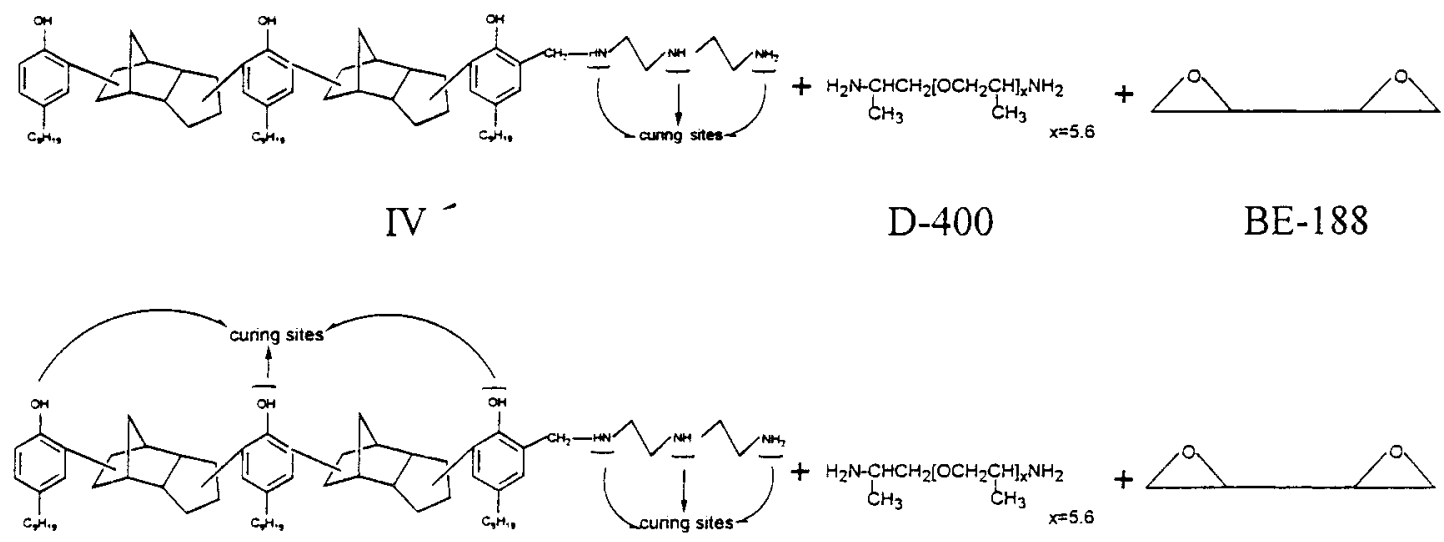

IV"

D-400

BE-188

the flexural modulus (2.7 GPa vs. $2.9 \mathrm{GPa}$ in Table III). The improved flexural modulus may be due to the rigid phenol component in the structures.

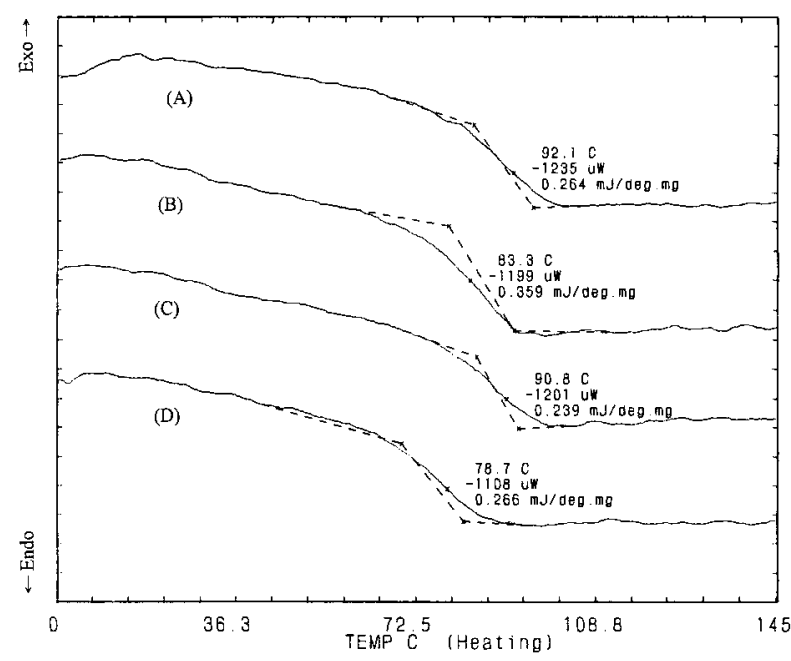

Figure 5 DSC thermograms of different cured polymers: (A) III'/BE-188; (B) III"/BE-188; (C) IV'/BE-188; (D) IV"/BE-188. lar to the corresponding results shown previously, the system involving $\mathrm{IV}^{\prime \prime}$ is inferior to that of IV'. The improvement may be made by finding a suitable catalyst for increasing the phenolic hydroxyl curing.

Furthermore, the presence of tricyclodecane should improve the flexibility. The expected results are not observed. This may be attributed to the polymers' orientation that DCPD exists in the pendant position rather than in the backbone.

\section{CONCLUSIONS}

A series of phenol/dicyclopentadiene (DCPD) adducts can be prepared from the reaction of $p$-nonylphenol and dicyclopentadiene at various molar ratios. The molecules contain tricyclodecane and multiple phenol functionalities. The consequent Mannich reaction using diethylenetriamine and formaldehyde gave rise to an epoxy curing agent containing phenol, amine, and tricyclodecane in the same molecule. Through the Mannich reaction, amines could add to the phenol at approximately $50 \%$ theoretical equivalents. As curing agents, the multiple amine 
Table III Properties of Cured Epoxy Involving Mannich Amine III and IV

\begin{tabular}{|c|c|c|c|c|c|c|}
\hline \multirow[b]{2}{*}{ Composition } & \multirow[b]{2}{*}{$\begin{array}{l}\text { Weight } \\
\text { Fraction }\end{array}$} & \multicolumn{2}{|c|}{ Tensile Properties } & \multicolumn{3}{|c|}{ Flexural Properties } \\
\hline & & $\begin{array}{l}\text { Tensile } \\
\text { Strength } \\
\text { (Mpa) }\end{array}$ & $\begin{array}{l}\text { Strain at } \\
\text { Break }(\%)\end{array}$ & $\begin{array}{c}\text { Flexural } \\
\text { Strength } \\
\text { (Mpa) }\end{array}$ & $\begin{array}{l}\text { Flexural } \\
\text { Modulus } \\
\text { (Mpa) }\end{array}$ & $\begin{array}{c}\text { Displacement } \\
\text { at Break } \\
(\mathrm{mm})\end{array}$ \\
\hline D-400/BE-188 & $35 / 65$ & $51.9(1.1)$ & $7.98(0.07)$ & $81.4^{\mathrm{a}}(0.3)$ & $2882(45)$ & - \\
\hline DETA/BE-188 & $10 / 90$ & $49.0(1.9)$ & $8.37(0.58)$ & $84.6^{\mathrm{a}}(5.8)$ & $2480(49)$ & - \\
\hline DETA/D-400/BE-188 & $5 / 18 / 77$ & $61.1(1.0)$ & $12.3(1.4)$ & $102^{\mathrm{a}} \quad(30)$ & $2742(76)$ & - \\
\hline III'/D-400/BE-188 & $29 / 13 / 58$ & $63.9(0.7)$ & $12.5(1.40)$ & 103.9 & $2945(18)$ & $14.00(0.35)$ \\
\hline III"/D-400/BE-188 & $25 / 12 / 63$ & $65.8(1.0)$ & $11.43(0.31)$ & 94.6 & $3109(97)$ & $8.32(1.15)$ \\
\hline IV'/D-400/BE-188 & $38.7 / 11.6 / 49.7$ & $67.8(0.4)$ & $11.53(0.13)$ & 102.5 & $2897(48)$ & $11.40(1.07)$ \\
\hline IV"/D-400/BE-188 & $32 / 10 / 58$ & $57.0(3.7)$ & $7.22(0.50)$ & $(2.6)$ & $3012(52)$ & $6.88(0.73)$ \\
\hline
\end{tabular}

a yield strength.

III': nonylphenol/dicyclopentadiene/formalin/DETA product at $2: 1: 2: 2$ molar ratio cured epoxy resin with the -NH functional group.

III": nonylphenol/dicyclopentadiene/formalin/DETA product at $2: 1: 2: 2$ molar ratio cured epoxy resin with the $-\mathrm{NH}+-\mathrm{OH}$ functional groups.

$\mathrm{IV}^{\prime}$ : nonylphenol/dicyclopentadiene/formalin/DETA product at $3: 2: 2: 2$ molar ratio cured epoxy resin with the $-\mathrm{NH}$ functional group.

IV": nonylphenol/dicyclopentadiene/formalin/DETA product at $3: 2: 2: 2$ molar ratio cured epoxy resin with the $-\mathrm{NH}+-\mathrm{OH}$ functional groups.

BE-188: diglycidyl ether of bisphenol A.

D-400: poly(oxypropylene) diamine or Jeffamine ${ }^{\mathrm{R}}$ D-400 at $400 M_{w}$.

DETA: diethylenetriamine.

$\mathrm{N}-\mathrm{H}$ and the phenol $\mathrm{O}-\mathrm{H}$ groups provided crosslinking sites for epoxy resins. An improvement in tensile strength and elongation has been shown by using these novel curing agents in comparison with poly(oxypropylene) diamine at 400 molecular weight and diethylenetriamine. The effect of the tricyclodecane in the structure on polymer flexibility are not observed.

Financial support by the Chinese Petroleum Company and the National Science Council of Taiwan is gratefully acknowledged.

\section{REFERENCES}

1. Santanna, C. M. R.; Ermel, E.; Quijada, J. R. Polym Bull 1992, 28, 47.

2. Sjaradijn, W.; Snel, J. J. M. U.S. Pat. 5, 248, 745 (1993).

3. Mori, S.; Fujimoto, K.; Tonoki, S. U.S. Pat. 5, 270, 104 (1993).

4. Matejka, L.; Houtman, C.; Macosko, C. W. J Appl Polym Sci 1985, 30, 2787.

5. Heroguez, V.; Soum, A.; Fontanille, M. Polymer 1992, 33, 3302.

6. Coffy, T. J. U.S. Pat. 5, 204, 420 (1993).
7. Kelsey, D. R.; Scardino, B. M.; Handlin, D. L., Jr. U.S. Pat. 5, 218, 065 (1993).

8. Kelsey, D. R.; Handlin, D. L., Jr. U.S. Pat. 5, 254, 629 (1993).

9. Yang, Y. S.; Lafontaine, E.; Mortaigne, B. Polymer 1997, 38, 1121.

10. Wang, C. S.; Bogan, G. W. U.S. Pat. 4, 663, 400 (1987).

11. Wang, C. S.; Chen, W. N.; Bowden, R. L.; Berman, J. R. U.S. Pat. 4, 684, 700 (1987).

12. Enomoto, M.; Kubota, S.; Oshimi, F.; Yuasa, H.; Otsuki, Y. U.S. Pat. 5, 344, 899 (1994).

13. Lee, H.; Nerville, K. Handbook of Epoxy Resin; McGraw-Hill: New York, 1967.

14. Makato, Y. Jpn. Pat. 8, 616, 8, 618 (1986).

15. Hishinuma, M. Jpn. Pat. 8, 629, 3, 219 (1986).

16. Hiroakt, N. Jpn. Pat. 8, 713, 5, 539 (1987).

17. Blicke, F. F. In Organic Reactions, vol. 1; J. Wiley and Sons: New York, 1942, p. 303.

18. Tramontini, M.; Angiolini, L.; Ghedini, N. Polymer 1988, 29, 771.

19. Leigh, D. A.; Linnae, P.; Jackson, G. Tetrahedron Lett 1993, 34, 5639.

20. Thompson, B. B. J Pharm Sci 1968, 57, 715.

21. Tramontini, M. Synthesis 1973, 703.

22. Hodgkin, J. H. J Polym Sci Part A Polym Chem 1986, 24, 3117.

23. Butler, G. B.; Hong, S. H. J Macromol Sci Chem 1987, A24, 919. 
24. Angiolini, L.; Ghedini, N.; Tramontini, M. Polym Commun 1985, 26, 218.

25. Brown, S. H.; Rafael, S.; Crocker, R. E. U.S. Pat. 3, 868, 329 (1975).

26. Roling, P. V.; Niu, J. H. Y.; Reid, D. K. U.S. Pat. 4, 810, 354 (1989).

27. Loper, J. T. U.S. Pat. 5, 387, 266 (1995).

28. Jamois, D.; Tessier, M.; Marechal, E. J Polym Sci Part A Polym Chem 1993, 31, 1941.

29. Suzuki, H.; Matsui, A.; Inoue, T. U.S. Pat. 3, 950, 451 (1976).

30. Becker, W. U.S. Pat. 3, 734, 965 (1973).

31. May, C. A. Epoxy Resins, Chemistry and Technology; Marcel Dekker, Inc.: New York, 1988.

32. Baffa, M. M.; Bull, C. H. U.S. Pat. 4, 659, 779 (1987).
33. Grigsby, R. A., Jr.; Speranza, G. P. U.S. Pat. 4, 714, 750 (1987).

34. Lin, J. J.; Speranza, G. P.; Waddill, H. G. J Polym Res 1996, 3, 97.

35. Nelson, D. L.; Jackson, L. U.S. Pat. 4, 390, 680 (1983).

36. Jamois, D.; Tessier, M.; Marechal, E. J Polym Sci Part A Polym Chem 1993, 31, 1923.

37. Jamois, D.; Tessier, M.; Marechal, E. J Polym Sci Part A Polym Chem 1993, 31, 1959.

38. Mijovic, J.; Kim, J.; Slaby, J. J Appl Polym Sci 1984, 29, 1449.

39. Morgan, R. J.; Happe, J. A.; Mones, E. T. 28th National SAMPE Symposium, April 12-14, 1983.

40. Ochi, M.; Bell, J. P. J Appl Polym Sci 1984, 29, 1381. 